\title{
Efficacy of treatment with Ombitasvir, Paritaprevir / R + Dasabuvir over 8 versus 12 weeks in chronic HCV hepatitis genotype 1b
}

\author{
Mircea Manuc ${ }^{1,2}$, Carmen Monica Predaa ${ }^{1,2}$, Laura Iliescu ${ }^{2,3}$, Doina Istratescu², \\ Andreea Elena Chifulescu ${ }^{2}$, Corina Silvia Pop ${ }^{3,4}$, Anca Trifan ${ }^{5,6}$, Carol Stanciu ${ }^{5,6}$, \\ Corneliu Petru Popescu ${ }^{7,8}$, Mircea-Mihai Diculescu ${ }^{1,2}$, Teodora Manuc ${ }^{1,2}$, \\ Letitia Tugui ${ }^{2}$, Elena Cianga ${ }^{2}$, Cristian George Tieranu ${ }^{1,9}$, Tudor Stroie ${ }^{2}$, \\ Liliana Simona Gheorghe ${ }^{1,2}$ \\ ${ }^{1}$ Gastroenterology \& Hepatology Department, \\ „Carol Davila" University of Medicine and Pharmacy, Bucharest, Romania \\ ${ }^{2}$ Fundeni Clinical Institute, Bucharest, Romania \\ IInternal Medicine Department, \\ "Carol Davila" University of Medicine and Pharmacy, Bucharest, Romania \\ ${ }^{4}$ University Emergency Hospital, Bucharest, Romania \\ ${ }^{5}$ Gastroenterology \& Hepatology Department, \\ "Gr.T. Popa“, University of Medicine and Pharmacy, lasi, Romania \\ ${ }^{6}$ Gastroenterology \& Hepatology Institute, lasi, Romania \\ ${ }^{7}$ Virology Department, „Carol Davila” University of Medicine and Pharmacy, Bucharest, Romania \\ ${ }^{8}$ "Victor Babes". Hospital, Bucharest, Romania \\ ${ }^{9}$ Elias Emergency Hospital, Bucharest, Romania
}

\begin{abstract}
Background and aims. For the 8-week OPrD regimen, real world data are insufficient. This study aims to compare the efficacy of the two types of regimens (12-week versus 8-week) in a real world cohort of patients with genotype $1 \mathrm{~b}$.

Material and methods. We analysed a multicentric retrospective cohort enrolling 1436 patients who started HCV therapy in 2018-2019. Liver fibrosis was staged in all subjects by Fibromax. Efficacy was assessed by the percentage of patients achieving SVR 12 weeks post-treatment (SVR12).

Results. Out of the 1436 analysed patients, 112 received 8 weeks therapy and 1324 received 12 weeks. In this cohort the proportion of male patients was $25.2 \%$, the median age 61 years, $28.2 \%$ were interferon pre-treated, and the rate of co-morbidities was $47 \% .42 \%$ of the subjects had F2 fibrosis, $29 \% \mathrm{~F} 1$ fibrosis, $16 \% \mathrm{~F} 3$ and $12 \% \mathrm{~F} 4$. The SVR rate was comparable in both groups of patients $(97 \%$ in those treated with OPrD 12 weeks vs $96.4 \%$ in those that received OPrD 8 weeks) (by intention-to-treat). In the 12 weeks arm, the drop-out rate was $0.8 \%$ and the rate of severe adverse events was $1 \%$, while in the arm of 8 weeks therapy there were no severe adverse events reported and no drop-out $(p=0.25)$. The only predictive factor for non-response in both treatment arms was the male sex.

Conclusions. OPrD 8 weeks proved to be highly efficient in our patients with a $96.4 \%$ SVR. No serious adverse events and no drop out were reported.
\end{abstract}

Keywords: Paritaprevir/Ombitasvir/Ritonavir/Dasabuvir, chronic hepatitis, hepatitis $\mathrm{C}$ virus $(\mathrm{HCV})$, direct acting antiviral agents (DAA) 


\section{INTRODUCTION}

Hepatitis $\mathrm{C}$ virus (HCV) infection is a major global health concern. In 2015, estimations indicated a $1 \%$ prevalence, with a total of 1.75 million new infections and 71 million chronic infections [1].

The estimated prevalence of virus $\mathrm{C}$ chronic infection In Romania, according to data published in 2010 was approximately 4\% [2], but it is decreasing now due to direct antiviral therapy received by approximately 35,000 patients with more than $96 \%$ achieving SVR [3-6]. In Romania the genotype 1b is almost exclusively present among the infected patients [7].

Currently, DAAs are the recommended treatment in clinical guidelines and according to WHO [8-12]. $\mathrm{HCV}$ can promote carcinogenesis and its eradication directly decreases HCC risk $[13,14]$. One of the regimens approved by the Food and Drug Administration (FDA) in 2014 for patients with genotype 1 chronic $\mathrm{HCV}$ infection is Ombitasvir/Paritaprevir/ritonavir + Dasabuvir (OPrD). It contains 3 direct-acting $\mathrm{HCV}$ antiviral agents: Ombitasvir (NS5A inhibitor), Paritaprevir (NS3/NS4A protease inhibitors), and Dasabuvir (NS5B non-nucleoside polymerase inhibitor) and a CYP3A inhibitor, Ritonavir, which although is not active on HCV, it acts as a pharmacokinetic enhancer, increasing plasma drug concentrations of Paritaprevir and drug exposure $[15,16]$. According to EASL guidelines, this regimen can be used in treatment-naïve or treatment-experienced patients, infected with genotype $1 \mathrm{~b}$, without cirrhosis or with compensated cirrhosis (Child-Pugh A) for 12 weeks, with the possibility of a shorter course of 8 weeks only in treatment-naïve patients with F0-F2 fibrosis [9].

Regarding the 8-week regimen, there is only one published clinical trial from 2017. The Garnet study was a multicenter, open-label, single arm, phase 3 trial that included 166 patients with chronic HCV infection, mostly genotype $1 \mathrm{~b}(98 \%)$, naïve to treatment and without cirrhosis who were treated for 8 weeks with OPrD. 162 (98\%) obtained sustained virologic response at 12 weeks post-treatment [17].

In the case of the 8-week regimen, data coming from real world experience (RWE) studies are insufficient: only two studies have been published to date, reporting $95-96 \%$ SVR rate $[18,19]$.

\section{AIM}

This study aims to compare the efficacy of the two types of regimens (12-week versus 8 -week) in a real world cohort in patients with genotype $1 b$.

\section{MATERIALS AND METHODS}

We analysed a multicentric retrospective cohort enrolling 1,436 patients who started the therapy between September 2018 and August 2019 in the Gastroenterology Department and Internal Medicine Department of Fundeni Clinic Institute, Gastroenterology\&Hepatology Institute Iasi, Internal Medicine Department of Emergency Universitary Hospital and Gastroenterology Department of Elias Emergency Hospital, all with genotype $1 \mathrm{~b}$ infection. The inclusion criteria were: chronic hepatitis $\mathrm{C}$, detectable HCV- RNA viral load in serum, no significant ethanol consumption in the last 3 months. All the potential drug-drug interactions were verified, and concomitant therapy was administered only if potential interactions were excluded. The choice of the regimen was at the discretion of the treating physicians.

Patients co-infected with hepatitis B virus received anti-HCV therapy if they had HBV- DNA viral load $<20 \mathrm{IU} / \mathrm{ml}$. Those with history of hepatocellular carcinoma were treated if they had absence of relapse 6 months after their last session of therapy (surgery or radiofrequency ablation or transarterial chemo embolization).

The fibrosis stage was confirmed by Fibromax testing in all patients. FibroMax ${ }^{\mathrm{TM}}$ (Biopredictive, Paris, France) is a non-invasive method for estimation of of the liver injury through of the association of three tests FibroTest ${ }^{\mathrm{TM}}$, SteatoTest ${ }^{\mathrm{TM}}$ and NashTest ${ }^{\mathrm{TM}}$, respectively. It is well validated for $\mathrm{HCV}$ (AUROC 0.87) [20].

Only serious adverse events leading to discontinuation of therapy were reported. Data were obtained from the database of each Institution.

The study was approved by the Ethics Committee of Fundeni Clinical Institute. All patients signed written informed consent before entering in the study.

\section{Main outcome measure}

Efficacy of the DAA therapy was assessed by the percentage of patients achieving SVR (HCV RNA undetectable) 12 weeks post-treatment (SVR12).

The recorded features for analysis were: age, sex, prior antiviral therapy (and the patients status: nonresponder or relapser), weight, height, body mass index, parameters calculated by Fibromax (fibrosis stage, steatosis score, necroinflammatory activity), presence of significant co morbidities, use of con- 
comitant medications. Laboratory data were recorded 3 months before starting the antiviral therapy. Analyzed parameters included total bilirubin, AST, ALT, glucose level, HBs antigen, HCV-RNA viral load.

All patients that finished the antiviral therapy performed HCV-RNA viral load 12 weeks after the completion of therapy. HCV RNA levels were assessed by quantitative PCR assays: COBAS TaqMan HCV v2.0 (Roche Molecular Diagnostics, Pleasanton, CA, USA).

All patients received two tablets of paritaprevir/ ombitasvir/ritonavir $(75 \mathrm{mg} / 12.5 / 50 \mathrm{mg}$ per tablet) once daily and Dasabuvir $250 \mathrm{mg}$ two tablets per day in combination Duration of therapy was either 8 either 12 weeks according to the therapeutic guidelines of the EASL and the manufacturer's recommendations [9].

\section{Statistical analysis}

The data analysis was done in intention-to-treat, using the SPSS statistical software (version 20.0 from IBM Corporation, Armonk, NY, USA). Results were summarized as median and minimum and maximum values for quantitative variables non-normally distributed, mean \pm SD if they were normally distributed or as numbers and percentages for categorical variables. We looked for differences concerning the independent variables by outcome in an univariate analysis, using Mann-Whitney $U$ test or Fisher's exact test, depending on variables. A two-sided hypothesis testing was used and a $p$ value of less than 0.05 was considered statistically significant.

\section{RESULTS}

Out of the 1,436 analysed patients, 112 received 8 weeks therapy and 1,324 received 12 weeks. 10 subjects from the 12weeks arm were lost to follow-up, and 13 patients stopped the antiviral therapy because of severe adverse events. In the 8 weeks arm there were no severe adverse events reported and no dropouts $(\mathrm{p}=0.25)$ (figure 1).

In the entire cohort, the proportion of male patients was $25.2 \%$, the median age was 61 years. $28.2 \%$ of patients were interferon pre-treated (most of them non-responders), and the rate of co-morbidities was $47 \%$ (the most prevalent were hypertension $33 \%$ and type 2 diabetes $-6 \%$ ). $1.6 \%$ were co-infected with hepatitis B virus and $0.3 \%$ had a history of previously treated hepatocellular carcinoma. Most of the patients were overweight or obese (68\%), with a median BMI of 26.3 . With regard to the severity of liver fibrosis estimated by Fibromax, $42 \%$ of the subjects had F2 fibrosis, 29\% F1 fibrosis, 16\% F3 and $12 \% \mathrm{~F} 4$.

Table 1 presents the comparative description of the two groups of patients.

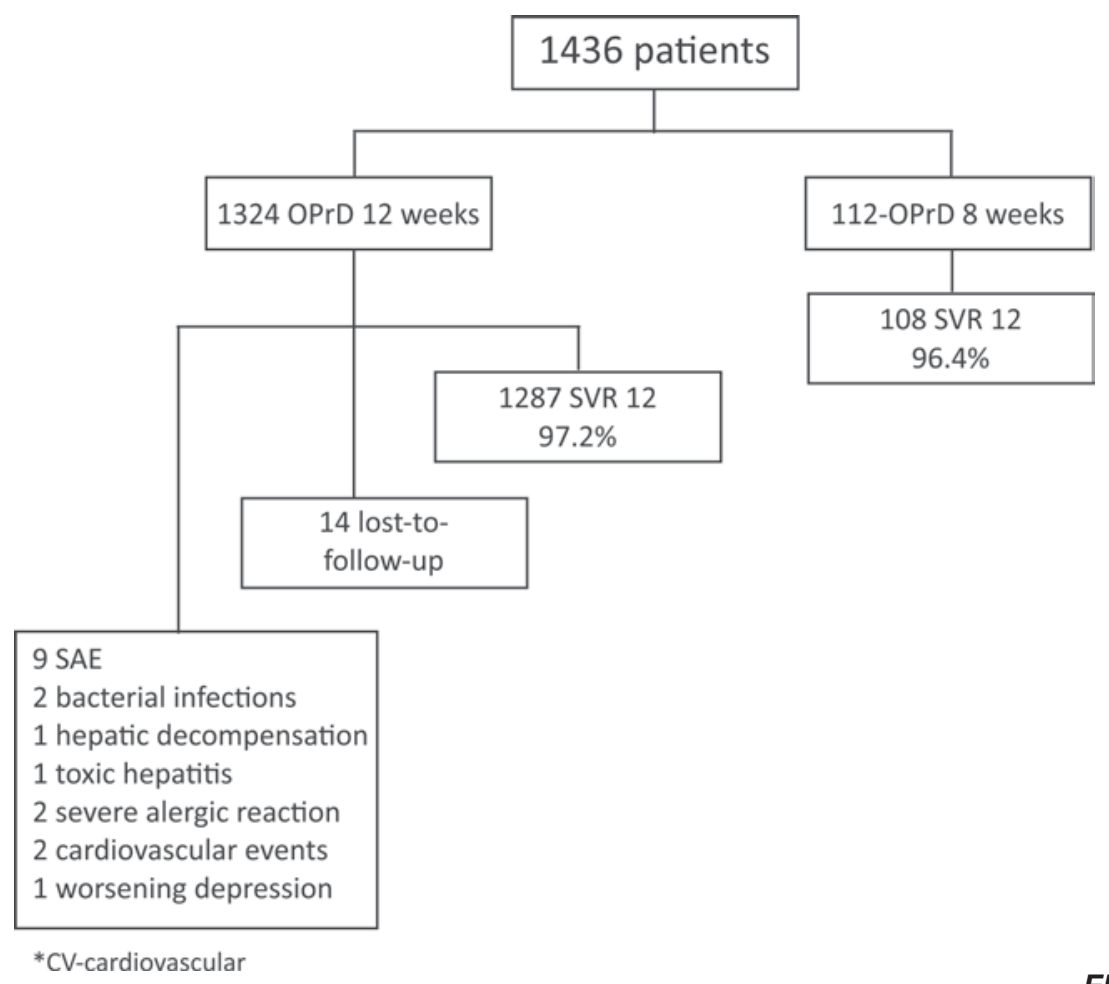


TABLE 1. Demographic and clinical features of patients with chronic hepatitis $C$ treated for 8 weeks vs.12 weeks with antiviral therapy (OPrD)

\begin{tabular}{|c|c|c|c|}
\hline Parameter & $\begin{array}{c}12 \text { weeks } \\
(1,324 \text { patients })\end{array}$ & $\begin{array}{c}8 \text { weeks } \\
\text { (112 patients) }\end{array}$ & p-value \\
\hline Sex M (\%) & $25.2 \%$ & $25 \%$ & 1.000 \\
\hline $\begin{array}{l}\text { Age } \\
\text { median (min. } \div \text { max.) }\end{array}$ & $\begin{array}{c}61 \\
(19 \div 87)\end{array}$ & $\begin{array}{c}52 \\
(20 \div 86)\end{array}$ & $<0.001$ \\
\hline $\begin{array}{l}\text { Severity of liver fibrosis } \\
\text { estimated by Fibromax (\%) } \\
(4 / 3 / 2 / 1 / 0)\end{array}$ & $\begin{array}{c}-12.4 \% \\
3-17.2 \% \\
2-42.1 \% \\
1-27.4 \% \\
0-0.9 \%\end{array}$ & $\begin{array}{c}-3.6 \% \\
3-2.7 \% \\
2-45.5 \% \\
1-46.4 \% \\
0-1.8 \%\end{array}$ & $<0.001$ \\
\hline Proportion of naive patients & $69.7 \%$ & $96.4 \%$ & $<0.001$ \\
\hline $\begin{array}{l}\text { Proportion of } 12 \text { weeks } \\
\text { responders (intention-to-treat) }\end{array}$ & $97 \%$ & $96.4 \%$ & 0.772 \\
\hline $\begin{array}{l}\text { Proportion of } 12 \text { weeks } \\
\text { responders (per protocol) }\end{array}$ & $98.9 \%$ & $96.4 \%$ & \\
\hline Severe adverse events & $0.7 \%(9 / 1324)$ & $0 \%$ & 0.292 \\
\hline Lost-to-follow-up & $1.1 \%(14 / 1324)$ & $0 \%$ & 0.356 \\
\hline Co-morbidities & $51.9 \%$ & $7.9 \%$ & $<0.001$ \\
\hline
\end{tabular}

The SVR rate was comparable in both groups ( $97 \%$ in those treated 12 weeks vs $96.4 \%$ in those treated 8 weeks) (by intention-to-treat). SVR rate per protocol in the 12 weeks treatment arm was 1286/1301 (98.9\%) (figure 2). There are significant differences between these 2 lots. Patients with a shorter treatment duration are significantly younger, with milder liver fibrosis and had no severe adverse events reported (table 1).

We searched for predictive factors of viral nonresponse in both treatment arms.

The only factor that predicted non-response to OPrD 8 weeks was the male sex. $75 \%$ of non-re- sponders were male compared to only $23 \%$ in responders (p-value 0.019). Non-alcoholic steatohepatitis and moderate-severe steatosis are much more prevalent in this subgroup of non-responders, but the values did not reach statistical signifficance. No other studied parameters could predict response to 8 weeks antiviral therapy (table 2). 7 patients from this 8 weeks treatment arm had advanced liver fibrosis (3 with F3, 4 with F4), and all of them were responders.

For the patients treated for 12 weeks, the only predictive factor for non-response was also the male sex. Frequency of non-alcoholic steatohepatitis and moderate-severe steatosis was increased among non-re-

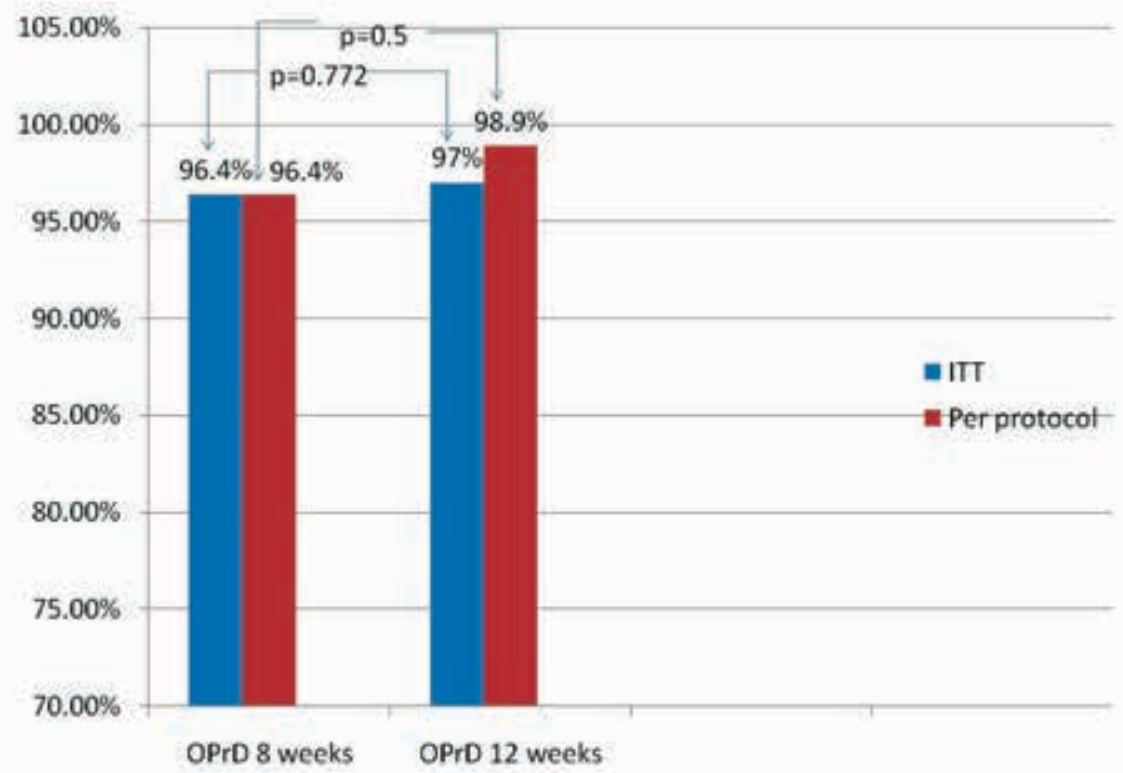

FIGURE 2. SVR 12 rates in intention-to-treat and per-protocol in the two groups of patients: 8 weeks therapy with OPrD versus 12 weeks with OPrD 
TABLE 2. Predictive factors of non-response to antiviral therapy in 112 patients with chronic hepatitis $C$ treated for 8 weeks with $\operatorname{OPrD}$ (multivariate analysis)

\begin{tabular}{|c|c|c|c|}
\hline Parameter & $\begin{array}{c}\text { Responders } \\
108\end{array}$ & $\begin{array}{c}\text { Non-responders } \\
4\end{array}$ & p-value \\
\hline Sex M (\%) & $25(23.1 \%)$ & $3(75 \%)$ & 0.019 \\
\hline Age * & $53(20 \div 86)$ & $45(26 \div 67)$ & 0.290 \\
\hline Fibrosis stage (\%) (0/1/2/3/4) & $\begin{array}{c}0-1.9 \% \\
1-45.4 \% \\
2-46.3 \% \\
3-2.8 \% \\
4-3.7 \%\end{array}$ & $\begin{array}{c}0-0 \% \\
1-75 \% \\
2-25 \% \\
3-0 \% \\
4-0 \% \\
\end{array}$ & 0.291 \\
\hline Proportion of naive patients & $104(96.3 \%)$ & $4(100 \%)$ & 0.696 \\
\hline $\begin{array}{l}\text { Severity of non-alcoholic } \\
\text { steatohepatitis estimated by } \\
\text { Fibromax }(\%)(0 / 1 / 2)\end{array}$ & $\begin{array}{c}0-65.6 \% \\
1-24.6 \% \\
2-9.8 \% \\
\end{array}$ & $\begin{array}{c}0-0 \% \\
1-50 \% \\
2-50 \% \\
\end{array}$ & 0.083 \\
\hline $\begin{array}{l}\text { Severity of liver steatosis estimated } \\
\text { by Fibromax (\%) }(0 / 1 / 2 / 3)\end{array}$ & $\begin{array}{c}0-45.9 \% \\
1-26.2 \% \\
2-19.7 \% \\
3-8.2 \% \\
\end{array}$ & $\begin{array}{l}0-0 \% \\
1-0 \% \\
2-50 \% \\
3-50 \% \\
\end{array}$ & 0.057 \\
\hline Proportion of co-morbidities & $6.6 \%$ & $50 \%$ & 0.332 \\
\hline AST (IU/L)* & $45(23 \div 131)$ & $77(29 \div 124)$ & 0.861 \\
\hline $\operatorname{ALT}(I U / L) *$ & $51(13 \div 270)$ & $143(49 \div 236)$ & 0.37 \\
\hline Blood glucose $(\mathrm{mg} / \mathrm{dl})^{*}$ & $94(77 \div 156)$ & $113(92 \div 133)$ & 0.35 \\
\hline HCV-RNA $(\mathrm{IU} / \mathrm{ml})^{*}$ & $623000(2978 \div 10812209)$ & $2843000(276000 \div 5410000)$ & 0.774 \\
\hline $\mathrm{BMI}\left(\mathrm{Kg} / \mathrm{m}^{2}\right)^{*}$ & $25.6(16.4 \div 40.3)$ & $29.9(26.6 \div 33.2)$ & 0.215 \\
\hline
\end{tabular}

*median (min. $\div$ max.)

sponders, but not statistically significant. No other studied parameter predicted the response to 12 weeks antiviral treatment.

\section{DISCUSSION}

Data from the literature suggest that OPrD is a highly efficient and safe therapy in patients with chronic hepatitis C [3,15-18].

The recomandation of treating naive patients infected with genotype $1 \mathrm{~b}$ with F0-F2 for 8 weeks with OPrD came from the GARNET study. In this trial the SVR12 rate was $97 \%(161 / 166)$ in treatment-naive patients with genotype $1 \mathrm{~b}$ infection and no cirrhosis (METAVIR score F0 to F3) after 8 weeks of OPrD treatment. Interestingly, among the 15 patients with F3 fibrosis included in this study, two experienced a virological failure. Our data show that all the 7 subjects with advanced liver fibrosis (3 with F3, 4 with F4) responded to antiviral therapy.

The attending physicians from our institutions gave 8 weeks therapy with OPrD to 4 Interferon-experienced individuals with hepatitis $\mathrm{C}$ ( 2 with F2 fibrosis, 2 with F1 fibrosis), and all of them were recorded with viral response.

Apart from the data obtained from clinical trials, which usually includes only highly selected patients, there are very few cohort studies with a low number of subjects, investigating the efficacy of 8 weeks OPrD in the real world $[18,19]$.

The cohort study coming from Poland reported efficacy data from 771 patients with genotype $1 \mathrm{~b} \mathrm{HCV}$ infection, with none to moderate fibrosis (197 treated for 8 weeks and 574 assigned to 12 weeks). The mean age of the Zarębska-Michaluk cohort was 47, and $43 \%$ were males, while in our cohort the median age was 61 years and only $25 \%$ were males [19]. Another real-life cohort study coming from Spain enrolled 211 patients from 23 Spanish centers: $42.5 \%$ males, with a median age of $57,75 \%$ with mild liver fibrosis F0-F1 and 25\% with moderate liver fibrosis (F2) [18].

Our different demographic and clinical data suggests that our national programme (2018-2019) treated mainly people infected before 1989, trough percutaneous/transfusion transmission. All our patients were evaluated trough Fibromax, and this allowed for a very thorough assessment, which included the evaluation of necroinflammation, the presence and severity of non-alcoholic steatohepatitis and of steatosis. The subjects included in the polish study were mainly evaluated trough transient elastography (56\%), and so were the patients included in the Spanish real-life study $[18,19]$. There are important differences between our two patient groups: the one with 
shorter treatment duration had a median age of 52 compared with $61,48 \%$ had mild or no fibrosis versus $28.3 \%, 96.4 \%$ were naive compared to $69.7 \%$, and the rate of comorbidities was $8 \%$ versus $52 \%$. Similarly, in the Polish cohort, the 2 treatment arms are not statistically comparable.

We obtained a statistically comparable SVR 12 rate in intention-to-treat: $97 \%$ in those treated for 12 weeks and $96.4 \%$ in patients with 8 weeks therapy duration. This is similar to results reported by Zarębska-Michaluk et al: 94\% (8 week duration) and 97\% (12 week duration) and to SVR obtained in the Spanish real-life study 96\% per ITT [18,19].

Regarding predictive factors for viral response, female sex was the only one statistically significant,for both treatment arms (8 weeks and 12 weeks). Puigvehi $\mathrm{M}$ et al found that the SVR rate was lower in males than in females ( $94 \%$ vs $98 \%$ ), even though this was not statistically significant [18]. The polish study reported also a trend for female sex to predict the response to antiviral treatment $(p=0.06)$ [19].

We encountered serious adverse events leading to therapy discontinuation only in patients treated for 12 weeks: $0.7 \%$, similar with the coming from ZarębskaMichaluk cohort (0.8\%).

Drop-out was recorded only in the subjects included in the 12 weeks therapy arm, and the rate was $1.1 \%$, while in the other 2 studies the drop-out rate was not specified $[18,19]$.

The main strength of our study is that it includes a relative high number of patients treated for 8 weeks in a very homogenous population: our subjects are only genotype $1 \mathrm{~b}, 96.4 \%$ naive and $93.7 \%$ with mild or no fibrosis (F0-F2). All patients were evaluated via Fibromax, providing important data for necroinflammatory activity, steatosis and non-alcoholic steatohepatitis.

OPrD treatment for 8 weeks was generally safe and well tolerated. An important limitation of our Conflict of interest: none declared Financial support: none declared

\section{REFERENCES}

1. WHO Global Hepatitis Report. Available at: https://www.afro.who.int/ sites/default/files/2017-06/9789241565455-eng.pdf.

2. Gheorghe L, Csiki IE, lacob S, et al. The prevalence and risk factors of hepatitis $C$ virus infection in adult population in Romania: a nationwide survey 2006-2008. J Gastrointestin Liver Dis. 2010 Dec;19(4):373-9.

3. Preda CM, Popescu CP, Baicus C, Voiosu TA, Manuc M, Pop CS, Gheorghe L, Sporea I, Trifan A, Tantau M, Tantau A, Ceausu E, Proca D, Constantinescu I, Ruta SM, Diculescu MM, Oproiu A. Real-world efficacy and safety of ombitasvir, paritaprevir/ study is the absence of a systematic prospective recording of adverse reactions. In our cohort of $112 \mathrm{pa}-$ tients, no serious adverse events leading to discontinuation of antiviral therapy were reported, similar with data from other cohorts $[18,19]$. Another study limitation was the lack of liver biology surveillance in time (at baseline, at EOT and at the SVR 12).

Very important, we have no data on HCV-RNA at EOT and we did not perform the analysis of treatment-emergent resistance associated variants (RAVs). However, according to Puigvehi M et al., all patients recorded as non-responders were relapsers, no breakthroughs occurred using $\mathrm{OPrD}$ during 8 weeks [18].

We have no data regarding non-compliance in patients that failed to respond, but, the fact that male sex is a predictive factor of non-response suggests that lack of compliance might be a cause of non-response.

\section{CONCLUSIONS}

OPrD for 8 weeks proved to be highly efficient in our population of patients with chronic hepatitis $\mathrm{C}$ genotype $1 \mathrm{~b}$ with mild to moderate fibrosis with a $96.4 \%$ SVR. No serious adverse events and no dropouts were reported. We found that male sex was the single predictive factor of non response in both groups. This study provides real-world evidence for excellent anti-viral potency of 8 weeks. Shortening of the treatment can lower the therapy costs, reduces the risk of adverse events and of drug-drug interactions and can improve patient adherence to treatment.

\section{Acknowledgement}

Liliana Simona Gheorghe, Laura Iliescu, Anca Trifan, Mircea Diculescu received honoraria and educational grants from Abbvie.

$\mathrm{r}+$ dasabuvir+ribavirin in genotype $1 \mathrm{~b}$ patients with hepatitis $\mathrm{C}$ virus cirrhosis. Liver Int. 2018 Apr;38(4):602-610.

4. Preda CM, Popescu CP, Baicus C, Constantinescu I, Oproiu A, Voiosu T, Diculescu M, Negreanu L, Gheorghe L, Sporea I, Trifan A, Ceausu E, Proca D, Manuc M. Risk of hepatitis B virus reactivation in hepatitis B virus + hepatitis $C$ virus-co-infected patients with compensated liver cirrhosis treated with ombitasvir, paritaprevir/ $\mathrm{r}+$ dasabuvir + ribavirin. J Viral Hepat. 2018 Jul;25(7):834-841.

5. Preda CM, Baicus C, Sandra I, et al. Recurrence rate of hepatocellular carcinoma (HCC) in patients with treated HCC and 
HCV-associated cirrhosis after Ombitasvir, Paritaprevir/ r+Dasabuvir+Ribavirin therapy. United European Gastroenterol J. 2019 Jun;7(5):699-708.

6. Gheorghe LS, Preda C, lliescu L, et al. Efficacy and Safety of Ledispavir/Sofosbuvir with or without Ribavirin in patients with Decompensated Liver Cirrhosis and Hepatitis C Infection: a Cohort Study. J Gastrointestin Liver Dis. 2020 Sep 9;29(3):385-390.

7. Manuc M, Preda CM, Popescu CP, et al. New epidemiologic data regarding hepatitis $C$ virus infection in Romania. J Gastrointestin Liver Dis. 2017 Dec;26(4):381-386.

8. World Health Organisation. Hepatitis C Fact sheet [Internet]. WHO. 2019. Available from: https://www.who.int/news-room/fact-sheets/ detail/hepatitis-c.

9. European Association for the Study of the Liver. EASL Recommendations on Treatment of Hepatitis C 2018. J Hepatol. 2018 Aug;69(2):461-511.

10. AASLD-IDSA Hepatitis C Guidance Panel. Hepatitis C Guidance 2019 Update: American Association for the Study of Liver Diseases - Infectious Diseases Society of America Recommendations for Testing, Managing, and Treating Hepatitis C Virus Infection. Hepatology. 2020 Feb 10;71(2):686-721.

11. Mar J, Ibarrondo O, Martínez-Baz I, et al. Economic evaluation of a population strategy for the treatment of chronic hepatitis $\mathrm{C}$ with direct-acting antivirals. Rev Esp Enferm Dig. 2018 Oct; 110(10):621-628.

12. Cabezas J, Llerena S, Puente Á, et al. Causes of treatment failure for hepatitis $C$ in the era of direct-acting antiviral therapy. Rev Esp Enferm Dig. 2016 Jul;108(7):421-30.

13. Sánchez-Torrijos $Y$, Ternero Vega JE, Cepeda Franco C. Hepatocellular carcinoma in patients without advanced fibrosis after
HCV eradication antiviral treatment. Rev Esp Enferm Dig. 2017 Oct;109(10):734-735.

14. Garrido-Serrano A, León R, Hernández A, et al. Hepatitis $C$ virus and hepatocellular carcinoma. Rev Esp Enferm Dig. 2011 May; 103(5):281-2.

15. Raedler LA. Viekira Pak (Ombitasvir, Paritaprevir, and Ritonavir Tablets; Dasabuvir Tablets): All-Oral Fixed Combination Approved for Genotype 1 Chronic Hepatitis C Infection. Am Health Drug Benefits. 2015 Mar;8(Spec Feature):142-7.

16. Iliescu EL, Mercan-Stanciu A, Toma L. Safety and efficacy of direct-acting antivirals for chronic hepatitis $\mathrm{C}$ in patients with chronic kidney disease. BMC Nephrol. 2020 Jan 16;21(1):21.

17. Welzel TM, Asselah T, Dumas EO, et al. Ombitasvir, paritaprevir, and ritonavir plus dasabuvir for 8 weeks in previously untreated patients with hepatitis $C$ virus genotype $1 \mathrm{~b}$ infection without cirrhosis (GARNET): a single-arm, open-label, phase $3 \mathrm{~b}$ trial. Lancet Gastroenterol Hepatol. 2017 Jul 1;2(7):494-500.

18. Puigvehí M, De Cuenca B, Viu A, et al. Eight weeks of Paritaprevir/r/ Ombitasvir + Dasabuvir in HCV genotype $1 \mathrm{~b}$ with mild-moderate fibrosis: Results from a real-world cohort. Liver Int. 2019 Jan 1;39(1):90-7.

19. Zarębska-Michaluk D, Piekarska A, Jaroszewicz J, et al. Comparative effectiveness of 8 versus 12 weeks of Ombitasvir/ Paritaprevir/ritonavir and Dasabuvir in treatment-naïve patients infected with HCV genotype $1 \mathrm{~b}$ with non-advanced hepatic fibrosis. Adv Med Sci. 2020 Mar 1;65(1):12-7.

20. EASL-ALEH Clinical Practice Guidelines: Non-invasive tests for evaluation of liver disease severity and prognosis. J Hepatol. 2015 Jul;63(1):237-64. 